\title{
A PHONOLOGICAL ANALYSIS OF THE EXPRESSIVE AND RECEPTIVE ARTICULATORY DIFFICULTIES OF AN APHASIC WITH APRAXIA OF SPEECH: A CASE STUDY.
}

\author{
AURA KAGAN, B.A. (SP. \& H. THERAPY) (WITWATERSRAND). \\ Dept. Speech Pathology and Audiology, \\ University of the Witwatersrand, Johannesburg.
}

\section{SUMMARY}

The expressive and receptive phonological errors of an aphasic subject with mild apraxia of speech were analysed in terms of a distinctive feature framework. The results indicated that errors could be characterized linguistically and that such information could be of therapeutic significance. The relationship between articulation problems and ability to discriminate phonemes was investigated. Although no direct relationship was found, discrimination errors followed linguistic trends demonstrated in the articulation errors. The findings of this study suggest that the traditional idea of apraxia as a non-linguistic and purely motor disorder needs re-examination.

\section{OPSOMMING}

Die ekspressiewe en reseptiewe fonologiese foute van 'n afatiese proefpersoon met matige spraakapraksie is ontleed in 'n raamwerk van distinktiewe eienskappe. Die uitslae dui aan dat foute linguisties gekaraktiseer kan word en dat die inligting dan van terapeutiese waarde kon wees. Die verwantskap tussen artikulasieprobleme en die vermoë om tussen foneme te diskrimineer is ondersoek. Alhoewel daar geen direkte verwantskap gevind is nie, het diskriminasiefoute dieselfde linguistiese neigings getoon as die artikulasiefoute. Die bevindings van hierdie studie dui aan dat die tradisionele begrip van apraksie as 'n nie-linguistiese en suiwer motoriese afwyking hersien behoort te woord.

Apraxia of speech has been considered to be a nonlinguistic disorder. ${ }^{27}$ For the purpose of this study, the term apraxia will be used as defined by De Renzi et al, ${ }^{7}$ who refer to oral apraxia as . . the inability to perform vol. untary movements with the muscles of the larynx, pharynx, tongue, lips and cheeks, although automatic movements of the same muscles are preserved.

The possibility of the application of phonological theory to apraxia occurring within the aphasic syndrome is felt to be of interest, as much recent work in the field of aphasia has indicated that articulation errors can be systematically described and analysed in terms of phonological theory. ${ }^{2}, 18,21,22,31$ It must be pointed out that there has been controversy as to the relevance of phonological theory in the field of aphasia. Critchley, ${ }^{4}$ for example, concludes that: To trace any rigid plan underlying the pattern of articulatory disorders in aphasic patients is premature. Spreen, ${ }^{33}$ however, points out that a phonological investigation of aphasia is valuable, as phonological errors, besides being of inherent linguistic interest, tend to confuse the study of higher-level speech functions.

The writer was interested in undertaking a phonological analysis of apraxic errors based on articulation trends derived from recent work in the field of 
aphasia and phonology. Some of this work has taken place within the framework of distinctive feature (DF) theory. ${ }^{2}, 21,22$ This theory, first proposed by Jakobson et al, ${ }^{13}$ and later developed by Chomsky and Halle, ${ }^{3}$ has at its foundation the belief that the distinctive features making up the phoneme are the basic units of language. Standel et al ${ }^{34}$ define distinctive features as . . . the smallest individual characteristic of a particular phoneme that can determine a difference between phonemes. Blumstein, ${ }^{2}$ as well as Martin and Rigrodsky, ${ }^{\overline{2}}$ found that the frequency of substitution errors made by aphasic subjects was inversely related to DF distance. Results of the latter study also revealed that errors on DF oppositions formed a definite hierarchy. Blumstein $^{2}$ also found that unmarked phonemes were substituted for marked pho. nemes more than vice-versa. The concept of 'markedness' in phonological theory is complicated and is defined differently within different theoretical frameworks. Blumstein ${ }^{2}$ introduces the idea of a hierarchical relationship between phonemes, the marked value being more complex than the unmarked or more basic value. She gives the example of the relationship between $/ \mathrm{p} /$ and / $b /$ where / $p /$ is the unmarked member to which the feature ( + voice) is added in order to obtain / $\mathrm{b} /$ which is thus marked in relation to $/ \mathrm{p} /$.

Another interesting feature of the application of phonological theory to aphasia arises from Jakobson's notions of the inverse relationship between childhood acquisition and aphasic dissolution of the phonological system. ${ }^{12}$ It was felt that it would be of value to investigate whether apraxic errors occurring within the aphasic syndrome could be analysed in terms of this theory. The writer was also interested in an analysis of the self-correction of articulation, as this presents us with an opportunity of observing phonological processing in action. In addition, self-correction embodies auditory discrimination, ${ }^{5,6}$ and thus the relationship between this analysis and the results of discrimination testing should be of interest.

It is felt that the application of phonological theory to apraxia could further our knowledge of this disorder, as the usefulness of conventional tests of articulation appears to be limited, particularly in cases where the apraxic element is of a milder or more subtle nature. The rationale for this study was thus to investigate whether a phonological approach would yield more meaningful results than conventional articulation tests of production and discrimination in the description and analysis of apraxic articulatory errors. The writer felt that if this did prove to be the case, such an approach could be effectively used in the drawing-up of therapy programmes for these patients.

\section{METHOD}

\section{SUBJECT (S)}

The $S$ used in this study was an adult White male aged 45 years. Severe aphasia involving apraxia developed as the result of the removal of infected braintissue. The infection set in after surgery to treat a subdural haemorrhage caused by trauma to the left cerebral hemisphere. The $S$ had been receiving speech therapy for two years and had improved greatly during this time. 
The $\mathrm{S}$ selected fulfilled the following criteria:

1) He was diagnosed as aphasic by a speech therapist and a neurologist. This was further confirmed by a formal rating on the Boston Diagnostic Test of Aphasia. ${ }^{10}$

2) Apraxic difficulties of a mild nature were experienced. A mild case was chosen as it was hoped that this would serve to highlight the value of a linguistic approach as compared to conventional testing.

3) Dysarthria was ruled out as being etiologically related to the articulation problem.

4) The $S$ had an adequate pre-morbid acquisition of speech and language.

5) Hearing was within normal limits.

AIMS

1) To investigate whether or not a DF analysis would be more successful than conventional tests in the description and analysis of apraxic articulatory errors.

2) To observe whether linguistic trends emerge in apraxic substitution errors as tested on a nonsense-syllable repetition task. (See [4] in section on tests employed for the rationale behind the use of nonsense syllables.) In particular, to investigate:

a) whether there is an inverse relationship between the number of errors and DF distance between the target phoneme and substitution error;

b) whether or not certain feature oppositions emerge as being more difficult than others;

c) if unmarked phonemes are substituted for marked phonemes more than vice-versa;

d) whether certain phonemes are substituted more often than others, regardless of the particular target phoneme;

e) whether attempts at self-correction move towards the target phoneme or if they are random.

3) To test discrimination of phonemes in nonsense syllables on a pointing task, in terms of findings on the nonsense-syllable repetition task.

4) To assess the value of a linguistic approach for therapy.

TESTS EMPLOYED IN THE STUDY (Construction, Administrative procedures and Scoring)

1. The Boston Diagnostic Aphasia Examination ${ }^{10}$

In addition to obtaining a formal confirmation of the clinical diagnosis of aphasia and assessing the degree of articulatory difficulty, this test was used in order to obtain a profile of scores on various linguistic dimensions. Administration followed the procedures laid down in the test manual.

2. The Goldman-Fristoe Test of Articulation. ${ }^{9}$

This was administered twice: a) conventionally, i.e. the $S$ was required to name pictured objects and describe pictured situations, and b) the $S$ had to repeat the names of objects or descriptions of situations after the Experimen- 
ter, (E). (See 2 in Results and Discussion for the rationale behind the two administrations of this test).

\section{Spontaneous Speech Sample}

Forty minutes of speech was elicited by requesting descriptions of pictures such as those from the Boston Diagnostic Aphasia Examination. ${ }^{10}$ The sample was recorded on a Sony Tape Recorder (TC 350).

\section{Nonsense Syllable Repetition Task}

Nonsense syllables were included in the test battery because, as pointed out by Martin and Rigrodsky, ${ }^{21}$ they might be more representative of a "purely phonological task' in that they exclude semantic factors. In addition, nonsense syllables have the advantage of being able to be systematically manipulated, e.g. each phoneme can be systematically tested in different positions and in the context of other phonemes.

In order to facilitate the drawing up of the nonsense syllables as well as subsequent analysis, computer programmes were constructed based on the DF Chart proposed by Chomsky and Halle. ${ }^{3}$ This theoretical framework was chosen as it is considered to be one of the most comprehensive to date. ${ }^{11}$ Only the consonantal system was investigated, which means that the number of relevant distinctive features was limited to eight of the original thirteen proposed, viz: ( \pm voice), $( \pm$ continuant $),( \pm$ nasal $),( \pm$ strident $),( \pm$ high $)$, ( \pm back), ( \pm anterior) and ( \pm coronal). Based on this, the following programmes were devised:-

a). All possible consonant contrasts grouped according to the DF distance between them, with a list of the features on which the differences occurred.

b). Contrasts grouped in terms of features (e.g. all contrasts involving ( \pm voice) in a hierarchy ranging from a difference of one distinctive feature upwards.)

c). Contrasts grouped in terms of particular phonemes (e.g. all contrasts involving $/ \mathrm{p} /$ ).

d). Contrasts grouped in terms of the order of differences (e.g. all contrasts involving $( \pm$ coronal $) ;( \pm$ coronal $)+( \pm$ voice $) ;( \pm$ coronal $)+( \pm$ voice $)$ $+( \pm$ continuant $)$.

The nonsense syllables were constructed as follows:

i. They consisted of 3 phonemes in CVC combinations.

ii. Initial and final consonants differed by at least three distinctive features (although in certain cases, contrasts of two distinctive features apart had to be used in order to avoid the formation of meaningful words). This was based on a finding by Lecours and Lhermitte ${ }^{18}$ that the likelihood of phonological error on a particular phoneme is directly related to the extent of its similarity to other phonemes in its immediate vicinity.

iii. Each phoneme was tested in the context of two vowels and two consonants (voiced-voiceless cognates). The feature ( \pm voice) was chosen because it is felt that its positive and negative values represented a clear acoustic and articulatory distinction. Specific vowels and consonants were chosen on the basis of avoiding the formation of meaningful words. 
It was hoped by the above procedure to control for the influence of contextual environment on the test-phoneme to some minimal extent.

iv. Each phoneme was tested in initial and final position. Where possible, the consonants were merely reversed, keeping the vowel constant, in order that only one variable be manipulated at a time, viz: position.

v. Where possible, phonemes were tested in blends (in initial position only). The blends were those used by Johnson, Darley and Spriestersbach $^{16}$ in their articulation test form, viz: $/ 1 /, / \mathrm{s} /$ and $/ \mathrm{r} /$. (See Table I for an example of nonsense syllable manipulation.)

\begin{tabular}{|c|c|c|}
\hline Initial position & Final position. & $\underline{\text { Blends }}$ \\
/kov/;/kif/ & /vok/;/fik/ & $/ \mathrm{krov} / ; / \mathrm{kriv} /$ \\
& & $/ \mathrm{klov} / ; / \mathrm{kliv} /$ \\
& & $/ \mathrm{skov} / ; / \mathrm{skiv} /$ \\
\hline
\end{tabular}

TABLE I: Example of the testing of the phoneme $/ \mathrm{k} /$.

Procedure for the testing of nonsense syllables:

a) The entire nonsense syllable test was administered twice: (i) in the early morning and (ii) in the late afternoon, each administration involving several sessions. Both the $S$ and the $E$ felt that testing in this manner sampled performance at its best and at its worst. Apraxia is, by its very definition, inconsistent. ${ }^{5,6}$ It seems logical therefore, to include the inconsistencies as part of the data. It is felt that many studies in the field of apraxia can be criticised for not repeating test procedures more than once. ${ }^{6,15}$

b) The $\mathrm{S}$ was required to repeat the nonsense syllables spoken by the $\mathrm{E}$. $\mathrm{He}$ was seated at right angles to the tester in such a manner as to obtain only auditory stimuli, as according to Johns and Darley, ${ }^{15}$ articulation proficiency is aided by the use of both auditory and visual modes of stimulation.

c) All substitution errors were noted. The decision to use this type of error was based on findings of recent research, ${ }^{21}$ where it has been found that substitutions (or commutation errors) occurred most frequently in nonsense-syllable repetition tasks.

d) The S's responses were noted by both the $\mathrm{E}$ and an observer. Wherever the two versions did not agree, the error was not included in the analysis. A tape-recorder was not used as this had been found to adversely affect the S's performance. For this same reason, the observer was a person familiar to the $S$.

\section{SCORING}

a) Responses were recorded phonologically and the results were tabled so as to give information about the DF distance between the target phoneme 
and substitution, as well as an indication of what these differences were. (See Table II.) A particular substitution had to occur at least twice before it was considered to be an error. A separate analysis of phoneme contexts and positions was felt to be beyond the scope of this study. These contexts and positions were included so that the phonemes could be tested under varied conditions. In this way, the results could not be attributed to variables external to the phoneme itself.

\begin{tabular}{|c|c|c|c|c|c|c|c|c|c|c|}
\hline $\begin{array}{l}\text { Target } \\
\text { Phoneme }\end{array}$ & $\underline{\text { Substitution }}$ & $\underline{\mathrm{v}}$. & $\underline{\text { Cont. }}$ & $\underline{\mathbf{N}}$. & $\underline{\mathbf{S}}$. & $\underline{\mathrm{H}}$. & B. & $\underline{\text { A. }}$ & $\underline{\mathrm{C}}$ & Total \\
\hline $\begin{array}{l}\mathrm{p} \\
\mathrm{p}\end{array}$ & $\begin{array}{c}\mathrm{m} \\
\mathrm{t}\end{array}$ & $*$ & & $*$ & & & & & * & $\begin{array}{l}2 \\
1\end{array}$ \\
\hline & Total & 1 & & 1 & & & & & 1 & \\
\hline
\end{tabular}

TABLE II: Example of the DF distance between target phoneme and substitution, with the features on which the phonemes differ.

In relation to Table II, a horizontal score tally gives the total DF distance between the target phoneme and substitution while a vertical score tally gives the number of times errors occurred on particular feature oppositions.

b) The latter results were ranked and Spearman's rank-order correlation test was performed between this result and that obtained by Martin and Rigrodsky ${ }^{22}$ on a similar task.

$\frac{\text { Target phoneme }}{p} \quad \frac{1 \text { st attempt }}{\mathrm{s}}$

Phoneme Contrasts

$$
\begin{aligned}
& p-s \\
& p-f \\
& p-t
\end{aligned}
$$

$\frac{\text { 2nd attempt }}{\mathrm{f}} \quad \frac{\text { 3rd attempt }}{\mathrm{t}}$

DF distance

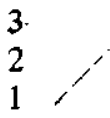

In this example, attempts at self-correction moved towards the target phoneme in terms of DF distance.

TABLE III: Example of the analysis of self-correction attempts.

c) Substitution errors were analysed in order to see whether voiceless and an- 
terior phonemes were used as substitutions more often than voiced and back phonemes.

d) Substitution errors were compared with the target phoneme in terms of whether unmarked features were substituted for marked features more than vice versa. Analyses were done on three different sets of data:

i) Phoneme contrasts involving a DF distance of 1, after Blumstein's procedure. $^{2}$

ii) Phoneme contrasts involving a DF distance of 1 but excluding all those involving the phoneme / $/$. An examination of the DF chart of Chomsky and Halle, ${ }^{3}$ reveals that / $\mathrm{p} /$ is the only phoneme with one positive distinctive feature (excluding the feature [ \pm consonantal] which is common to all phonemes used in this study). Therefore, it is theoretically impossible for $/ \mathrm{p} /$ to be substituted for by an unmarked phoneme; as such a phoneme would have no positive dis. tinctive features. It was therefore felt that the inclusion of $/ p /$ may bias the results.

iii) All phoneme contrasts. For this purpose, the marked phoneme of the pair was defined as the one with more positive distinctive features.

Both (ii) and (iii) represent extensions of the procedure used by Blumstein. ${ }^{2}$

e) Attempts at self-correction were analysed in terms of whether they moved towards the target phoneme or not. (see Table III.)

General points regarding procedure:

Testing took place over approximately fourteen hours, involving thirty-eight sessions. Testing sessions were short, the exact time involved depending on the S's reaction. The experimental procedure was made as flexible as was practical in order to elicit maximal performance. The test atmosphere was relaxed and informal so that variables such as test anxiety would not contaminate the results. This approach to testing has been supported by authorities such as Schuell et al. ${ }^{30}$

Although discrimination testing formed a large part of this study, it is not within the scope of this paper to discuss it in depth. A brief summary of pro. cedures and results of discrimination testing can be found at the end of the following section.

\section{RESULTS AND DISCUSSION}

\section{The Boston Diagnostic Aphasia Examination}

The $S$ received a severity rating of 2 , which, according to Goodglass and Kaplan, ${ }^{10}$ indicates that there are . . . frequent failures to convey the idea, but patient shares the burden of communication with the examiner. Although it was difficult to give the profile a specific label as the scores did not fall into an easily recognisable stereotype, the use of a score profile is felt to be a great advantage of this test as it enables one to see the relationship between various areas of deficit. It is felt, however, that the test is lacking in the depth required 
for planning detailed therapy procedures. For example, the writer found it difficult to obtain an in-depth picture of the articulatory difficulties of the $S$.

\section{The Goldman-Fristoe Test of Articulation}

Neither this test nor the spontaneous speech sample are discussed in detail as they do not form the focus of the study, but were used to reveal the fact that conventional testing procedures were not always suitable for ascertaining the extent of the subtle articulation difficulty being experienced by the $\mathrm{S}$. Errors made in response to the conventional administration of the Goldman-Fristoe Test ${ }^{9}$ were felt to be related to naming difficulties rather than to articulation problems. For example, when shown a picture of a 'house', the S responded with: "Building - no, to live - as usual I can't remember - box . . ." When the test was modified in such a way that the $S$ repeated the name after the $E$, he managed successfully in almost every case.

\section{Spontaneous speech sample}

Surprisingly, only 5 substitution errors were noted in this forty-minute speech sample. Possible explanations relate to the help afforded by semantic content, pictures which did not require much interpretative skill, and the relaxed, informal atmosphere of the test situation. As well as this, the $S$ had the choice of production under his control.

Based on the results of the above two tests, it might have been decided that the $\mathrm{S}$ did not have phonological problems. However, the clinical observations that the S's articulatory performance did in fact break down under difficult conditions (e.g. when tired, upset, nervous, speaking to strangers or describing specific situations), indicated that more sensitive testing was required.

\section{Nonsense Syllable Repetition Task}

(a) The relationship between number of errors and DF distance. As seen in Figure 1, there is an inverse trend in the relationship between error frequency

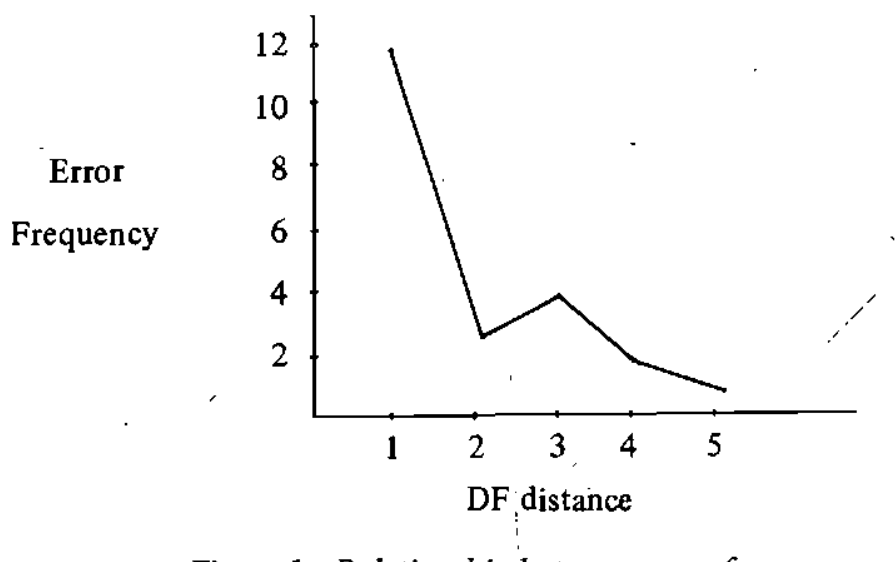

Figure 1: Relationship between error frequency and DF distance between target phoneme and substitution error. 
and DF distance, confirming the results of the studies of Blumstein ${ }^{2}$ and Martin and Rigrodsky. ${ }^{22}$ Most errors occurred on a DF distance of 1 and least on 5 .

According to Blumstein, ${ }^{2}$ an essential notion in DF theory is that phonemes with a DF distance of 1 are more similar . . . structurally, motorically and acoustically, as well as psychologically ... than phonemes with a larger DF difference. Lecours and Lhermitte ${ }^{18}$ in their measures of paradigmatic distance, based on five parameters, found that most substitution errors occurred between morphologically similar phonemic units. Although it is difficult to compare the results of studies based on different theoretical frameworks, it is . interesting to note the similarity. of general tendencies. This leads the writer to believe that we are dealing with psychologically valid phenomena and not merely results determined by particular theories.

Although most errors did occur between similar phonemes in terms of the DF framework of Chomsky and Halle, ${ }^{3}$ this theory could not explain certain substitution errors with a larger DF distance. Some of these are better explained by the Jakobsonian framework. ${ }^{11,13}$ It seems, for example, that in certain instances acoustic dimensions do function as superior explanatory tools, e.g. with $/ \mathrm{g} /-/ \mathrm{b} / ; / \mathrm{k} /-/ \mathrm{p} / ; / \mathrm{g} /-/ \mathrm{m} /$, all have a DF distance of 3 in terms of Chomsky and Halle's theory, ${ }^{3}$ but in terms of the Jakobsonian DF framework, ${ }^{11}$ labials and velars share the property of (+ grave) or "low tonality', and are thus close in acoustic terms.

The finding that substitution errors are not random. but are in most cases similar to the stimulus, leads the writer to feel, in common with Martin, ${ }^{20}$ that apraxia of speech within the aphasic syndrome is a linguistic disorder and should as such be considered as an integral part of the aphasic impairment. This finding has important implications for therapy and suggests that the difficulties might be amenable to DF therapy.

(b) Hierarchy of feature opposition difficulty:

Table IV indicates that certain features emerge as being more difficult than others. These results were correlated with those found by Martin and Rigrodsky. ${ }^{22}$ The correlation was not significant $\left(r_{S}=0.38 p>0.05\right)$. This serves as a reminder that care must be exercised before generalizing from the results of

\begin{tabular}{|lcc|}
\hline Fearure & No. of errors & Rank \\
\hline Coronal & 11 & 1 \\
Anterior & 7 & 2 \\
High & 6 \\
Back & 6 & 3 \\
Voice & 5 & 4 \\
Strident & 4 & 5 \\
Nasal & 3 & 6 \\
Continuant & 1 & 7 \\
\hline
\end{tabular}

TABLE IV: Hierarchy of difficulty on feature oppositions 
research to the individual patient. General trends are useful as an indication of what to expect, based on the average scores of many Ss. They cannot predict with complete accuracy, the performance of any one individual.

Although the writer recognises the inconsistency of apraxic articulation errors, the fact that the phonemes were tested in different contexts at different times, makes it possible to draw tentative conclusions relevant to the planning of therapy for this patient. Table IV presents a hierarchy of difficulty through which to work. The writer feels that these features themselves can be systematically analysed to give specific starting points for therapy. This point is discussed in detail at a later stage in this paper.

(c) Analysis of substitution errors:

According to Jakobson, ${ }^{12}$ phonological disintegration in the aphasic is an 'exact mirror-image' of phonological acquisition in the child. Other authorities, such as Critchley ${ }^{8}$ disagree with this point of view. In order to investigate Jakobson's hypothesis, one should select trends which have been well established as characteristic of the childhood acquisition of sounds. Hyman ${ }^{11}$ feels that certain of the trends observed by Jakobson are reliable, although the details have not always been supported by recent studies. He gives as examples, the acquisition of voiceless before voiced stops, as well as the acquisition of front before back consonants. If Jakobson's theory ${ }^{12}$ is valid, one would expect the aphasic to find voiceless and anterior phonemes easier than voiced and back phonemes, and would therefore predict that they would be used more frequently as substitutions.

The results obtained indicate that voiceless stops were substituted more than their voiced cognates in every case (Figure 2) and anterior phonemes were used as substitutions more frequently than back phonemes (Figure 3). Figure 2 also indicates that this trend applied to voiced-voiceless cognates other than stops. It is interesting to note that within the markedness theory of generative phonology, voiceless stops are 'universally less marked' than their voiced cognates. ${ }^{11}$

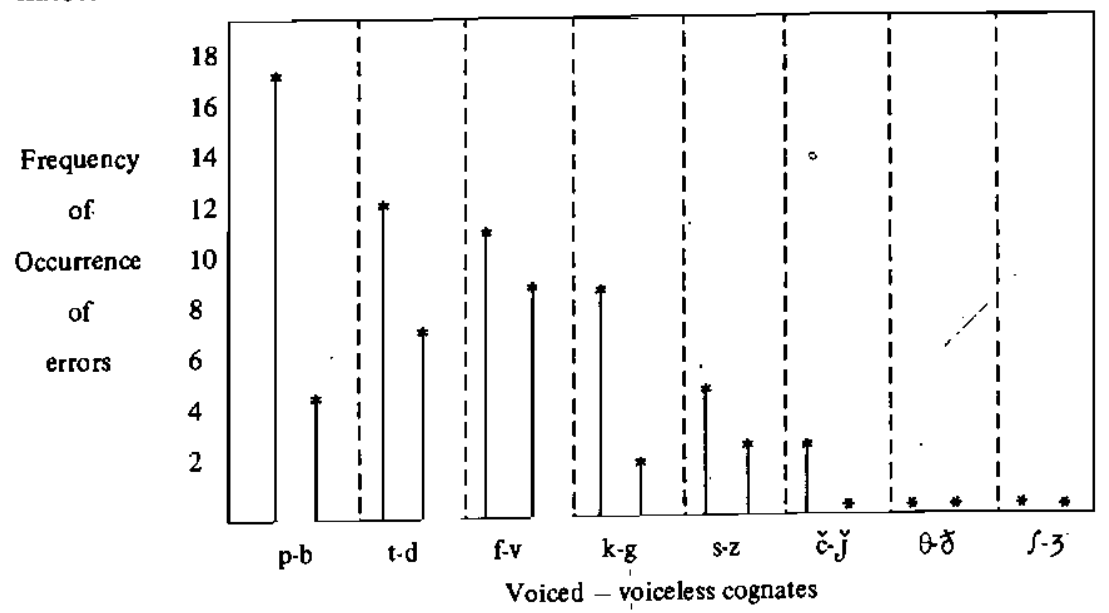

Figure 2: Voiced compared to voiceless substitution errors 


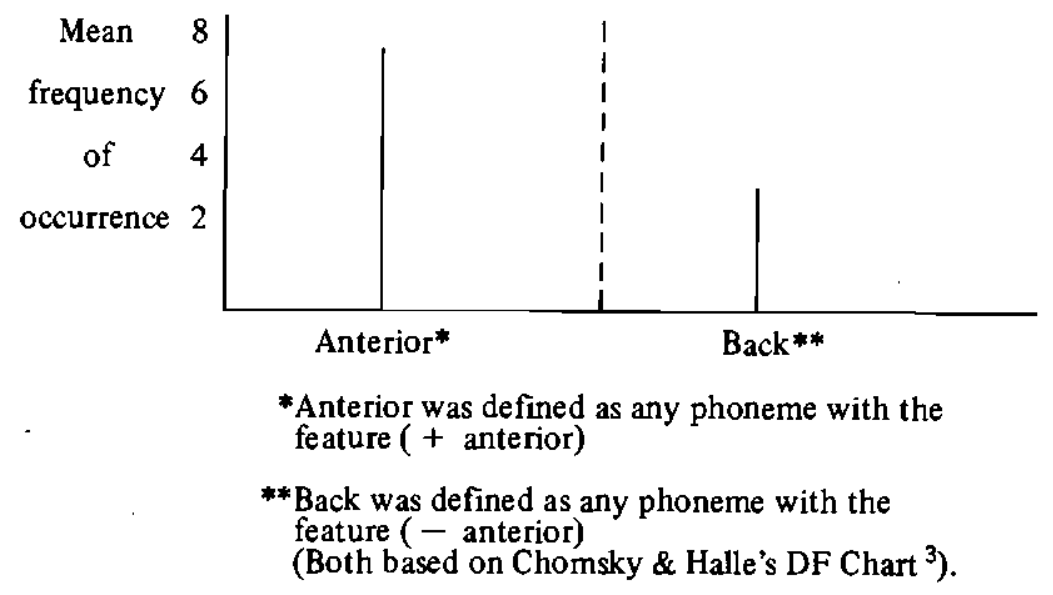

Figure 3: Anterior compared to back substitution errors.

(d) Markedness Analysis:

Figure 4 represents the trend for unmarked phonemes to be substituted for marked phonemes more than vice-versa, using three different manipulations of the substitution errors made by the $\mathrm{S}$. Theoretically these results are significant, as they lend credence to the idea put forward by Chomsky and Halle ${ }^{3}$ that ... unmarked features do not add to the complexity of a grammar. The writer agrees with Blumstein ${ }^{2}$ that such results can be seen within the general trend in aphasia towards ... simplification of the phonological system.

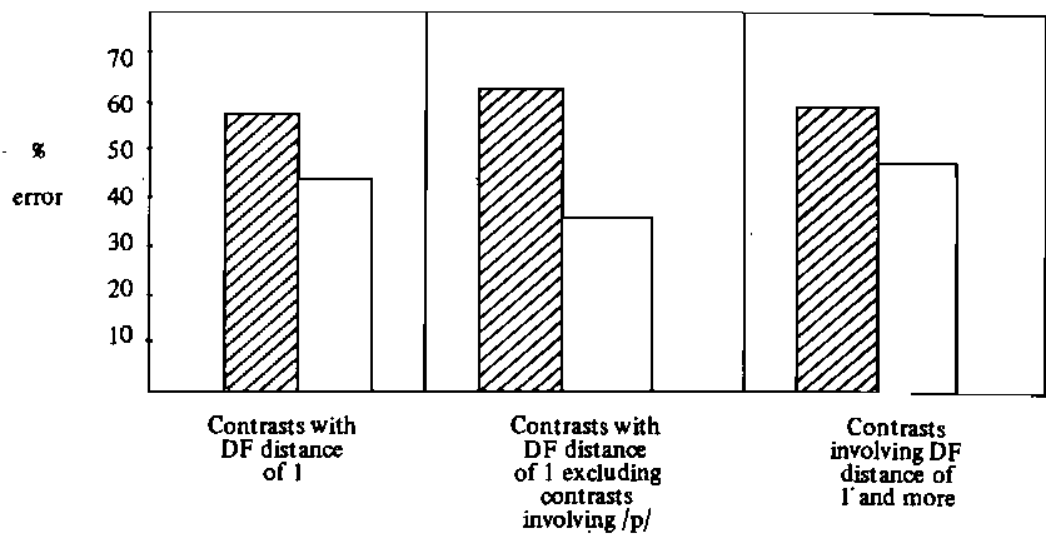

Key: $\square Z$ :Marked to unmarked $\square$ : Unmarked to marked

Figure 4: Markedness analysis - a comparison of substitution error to target phoneme 


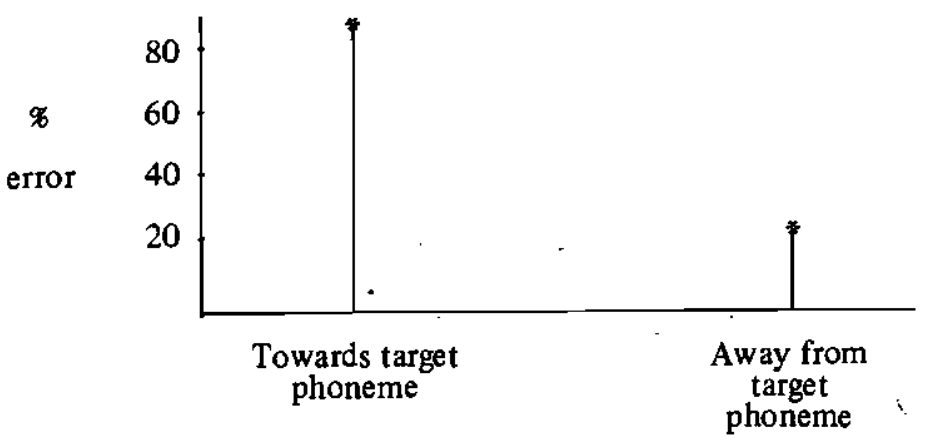

Figure 5: Analysis of self-correction errors

(e) Analysis of the process of spontaneous self-correction:

The results in Figure 5 indicate that in the majority of cases, attempts at selfcorrection move towards the target phoneme in terms of DF distance. This is an interesting result as it appears to tap an ongoing phonological process rather than examining a static structure. The writer feels that these results indicate the applicability of distinctive features, which are an abstract concept, to a psychologically real process. In his efforts to reach the target, the $S$ did appear to be using distinctive features. This is felt to be a striking example of the fact that the apraxic errors in this aphasic $S$ could be linguistically characterised, and implies that linguistics, or more specifically, phonological theory, could be of use in planning therapy for him.

\section{The concept of a Feature Opposition Chart as an Aid to DF Therapy}

Before discussing this procedure, it is felt that the use of DF therapy in aphasia needs justification. Much recent work in the field of articulation difficulties in children has been involved with an application of phonological theory. $24,25,26$ Most studies seem to be based on Jakobson's idea that childhood acquisition of phonology can be seen in terms of the acquisition of feature contrasts. If one accepts Jakobson's theory ${ }^{12}$ about the relationship between aphasia and childhood language, it is possible that the dissolution of the phonological system in aphasia could be viewed in terms of the loss of feature contrasts. The results of this study show that the apraxic errors of an aphasic patient can be usefully described and analysed within a DF framework. It séems logical, therefore, to attempt to remediate within the same framework. It must be pointed out that there have been criticisms of this approach. Walsh, ${ }^{35}$ for example, feels that distinctive features are too abstract to be clinically useful.

Based on the finding that most of this S's errors occurred on the feature ( \pm coronal), a Coronal Feature Opposition Chart was devised as an aid to therapy. The chart is a representation of all possible contrasts involving ( \pm coronal) in terms of Chomsky and Halle's theory. ${ }^{3}$ 


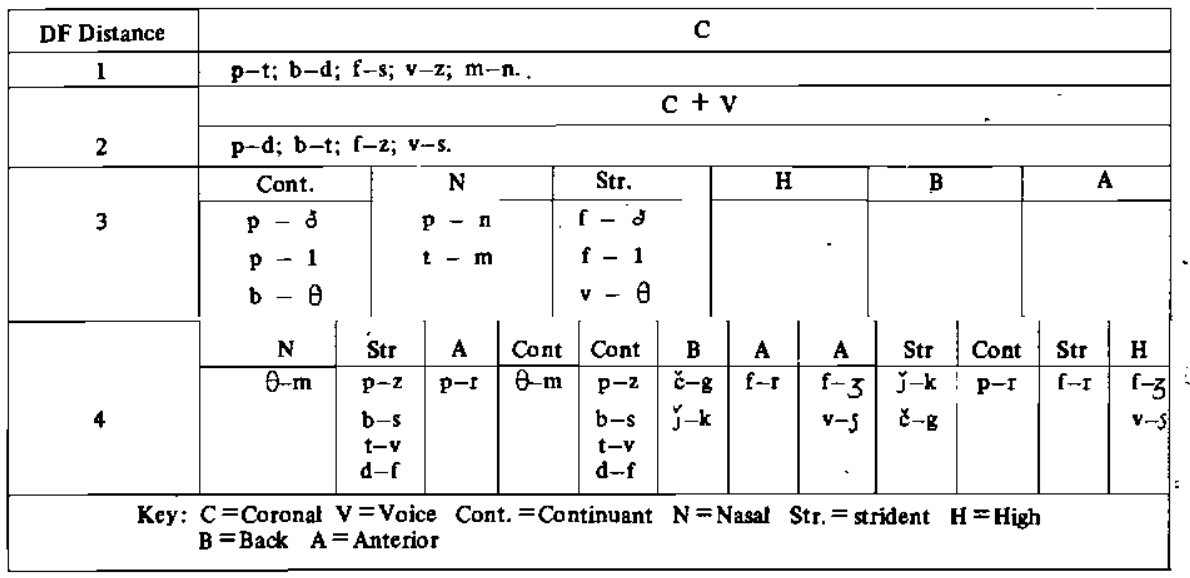

TABLE V: Example of part of the Coronal Feature Opposition Chart.

Similar charts could be drawn up for any feature. The chart can be used to describe DF distance as well as to see the effects of particular feature combinations.

As previously noted, most substitution errors occurred between phonemes with a DF distance of 1 and least between phonemes with a DF distance of 5 . Therefore, when beginning distinctive-feature therapy, one would initially choose contrasts with a large DF difference, gradually and systernatically decreasing this until the patient can contrast differences of 1 distinctive feature. Winitz ${ }^{36}$ mentions a similar principle with reference to 'phonetic' distance.

If $\mathrm{DF}$ training is to begin with phonemes having a DF distance of more than 1 , it becomes necessary to analyse the effects of various features in combination with the coronal feature. For example, if at a DF level of 2 , the $S$ makes least errors when the coronal feature is combined with voice, therapy could begin with this combination. Looking at the chart for coronal plus voice (See Table V), one can systematically select particular phoneme contrasts for inclusion in the DF therapy programme. In general, one would work from greatest to smallest DF distance. In addition, within each DF level, one should work within a hierarchy of difficulty as presented by each individual case. An example of a hierarchy of difficulty, working from the greatest to the smallest DF difference, would be the following:

Coronal, Voice, Continuant, Strident, e.g. p-z

Coronal, Voice, Continuant, e.g. p-1

Coronal, Voice, e.g. p-d

Coronal, e.g. p-t 
A Feature Opposition Chart can be used to represent both errors of articulation and discrimination. By marking the errors on the chart, one is provided with an instant visual indication of feature confusions.

\section{Summary of the procedures and results of discrimination testing.}

Discrimination was first tested conventionally on a modified version of the D.I.P. test. ${ }^{32}$ Modifications were made to those Americanisms felt to be confusing for the $S$. The $S$ made only 4 errors but as in the case of the repetition task, it was felt that deeper testing, using a phonological approach, would re. veal the fact that difficulty was being experienced in this area.

Therefore, a discrimination task was devised which involved pointing to one of two visually presented nonsense syllables, following an auditory stimulus given by the $\mathrm{E}$. Nonsense syllables were devised in the same manner as that described in the repetition task. Each contrast was tested twice and the order of presentation in terms of spatial cues within the contrasts was randomized. The two stimuli were identified by the $\mathrm{E}$ before the contrast was tested so that errors could not be attributed to problems of visual recognition.

The following discrimination tests were administered:-

a) The discrimination of phoneme contrasts with a DF distance of 1 which were confused on the repetition task was compared to the discrimination of phoneme contrasts having an identical DF distance not derived from articulation errors. The DF distance of 1 was chosen because most errors occurred here.

b) In terms of findings on the nonsense-syllable repetition task, the discrimination of all possible contrasts with a DF distance of 1 was compared with the discrimination of all possible contrasts involving a DF distance of 5.

Results for a) and b) were scored in terms of i) correct/incorrect from which a percentage of error was derived, and ii) reaction time (RT), defined as the time taken between the auditory stimulus being given by the $E$ and the $S$ 's pointing to one of the nonsense syllables, irrespective of whether it was correct or incorrect. It was hypothesized that RT would be a function of the 'difficulty' or 'complexity' of the stimulus. RT was measured with a stopwatch and was calculated to the nearest $1 / 10$ th second. The mean $(\bar{x})$, standard deviation (S.D.) and range of each set of RT scores was computed, the range being defined as $\bar{x}-1$ S.D. ${ }^{28}$

\begin{tabular}{|c|c|c|c|c|}
\hline Stimuli & क Error & $\overline{\mathrm{x}} \mathrm{RT}$ & SD & Ránge \\
\hline $\begin{array}{l}\text { Substitution error - } \\
\text { target phoneme }\end{array}$ & 40 & 1,82 &, 33 & $1,49-2,15$ \\
\hline Other contrasts & 29 & 1,75 &, 33 & $1,42-2,08$ \\
\hline
\end{tabular}

TABLE VI: A comparison between phoneme pairs derived from substitution errors with pairs not derived from substitution errors (all having a DF distance of 1) 
The results in Table VI indicate that the $S$ did find the discrimination of his errors slightly more difficult as indicated by a larger percentage error score and longer RT. However, this difference is not considered to be reliable, as the range of scores in both cases overlapped considerably. ${ }^{28}$

The difference between discrimination of phoneme pairs with a DF distance of 1 compared to those with a DF distance of 5 (Table VII) appears to be reliable, as indicated by a larger difference in the percentage error score and RT as well as by the fact that the range of scores hardly overlapped. ${ }^{28}$

\begin{tabular}{|c|c|c|c|c|}
\hline DF distance & \% Error & $\overline{\mathrm{x}} \mathrm{RT}$ & $\mathrm{SD}$ & Range \\
\cline { 2 - 4 } $\mathbf{1}$ & 26 & 1,22 &, 24 & $0,98-1,46$ \\
\hline
\end{tabular}

TABLE VII: A comparison between the discrimination of all phoneme pairs having a DF distance of 1 with all phonemes having a DF distance of 5

These two findings seem to be indicative of different aspects of discrimination. The results in Table VI are felt to reflect the lack of a direct relationship between articulation and discrimination in this $S$. This is surprising in terms of the views put forward by authorities such as Lieberman ${ }^{19}$ and Ladefoged et al, ${ }^{17}$ who stress the direct relationship between articulation and auditory perception (although their theories tend to emphasize different aspects of this). The results in Table VII are felt to indicate the existence of an indirect relationship between articulation and discrimination in the $S$. As can be seen, the trend for error frequency to be inversely related to DF distance followed that found in the analysis of articulatory substitution errors, i.e. phoneme contrasts with a DF distance of 1 resulted in more errors and a longer RT than phonemes with a DF distance of 5 .

\section{CONCLUSIONS}

Articulation errors made by the $S$ were able to be described and analysed within a linguistic framework which provides support for the view put forward by Martin ${ }^{20}$ that apraxia of speech is a linguistic disorder. This implies that apraxia could be considered an integral part of the aphasic breakdown, necessitating a linguistic approach to testing and therapy. Johns and Darley, ${ }^{15}$ on the other hand, feel that apraxia of speech requires a different therapeutic approach to that used in aphasia.

The results of the DF analysis on the nonsense syllable task appear to approx. imate the real-life performance of this $S$ better than the results of conven. tional tests which were unable to tap the subtle phonological difficulties being experienced.

The $\mathrm{S}$ did demonstrate problems of auditory discrimination, but these were not directly related to the articulation errors, according to the results of this 
study. The writer feels that, as yet, we do not have enough information to make emphatic statements about the lack of a one-to-one relationship between articulation and discrimination in apraxia. In order to do so, one should test discrimination of an error at the instant that it is produced. Testing the discrimination of errors at a later stage has an inherent limitation in view of the inconsistent nature of apraxic errors. It does, however, seem that there is some involvement of auditory perceptual difficulty in this $S$, which should be taken into account when planning therapy. The writer agrees with the views of Martin et $\mathbf{a l}^{\mathbf{2 3}}$ who feel that aphasia is characterized by an impairment of the interaction of several processes rather than impairment of an isolated aspect of functioning.

Although the use of Feature Opposition Charts involves a great deal of work on the part of the clinician, its great advantage lies in the fact that it allows the patient to demonstrate his idiosyncratic phonological difficulties in great detail, which should lead to the planning of more effective therapy. Further research may serve to refine these charts in order to make them more clinically practical.

It should be pointed out that the proposed approach in this study need not be limited to apraxia of speech, but should prove useful in many cases involving multiple articulation disorders.

\section{REFERENCES}

1. Aten, J. L., Johns, D. F. \& Darley, F. L. (1971): Auditory perception of sequenced words in apraxia of speech.J. Speech Hear. Res., 14(1) 131-143.

2. Blumstein, S.(1973): Some phonological implications of aphasic speech. In Psycholinguistics and Aphasia, Goodglass, H. \& Blumstein, S. (Eds.) The Johns Hopkins University Press, Baltimore.

3. Chomsky, N. \& Halle, M. (1968): The Sound Pattern of English. Harper \& Row, New York.

4. Critchley, M. (1973): Articulatory defects in aphasia: The problem of Broca's aphemia. In Psycholinguistics and Aphasia, Goodglass H. \& Blumstein, S. (Eds.) The Johns Hopkins University Press, Baltimore.

5. Darley, F. L. (1968): Apraxia of Speech: 107 years of terminological confusion. Paper presented to the American Speech and Hearing Association Convention.

6. Deal, J. L. \& Darley, F. L. (1972): The influence of linguistic and situational variables on phonemic accuracy in apraxia of speech.J. Speech Hear. Res., 15(3), 639-653.

7. De Renzi, E., Pieczuro, A. \& Vignolo, L. A. (1966): Oral apraxia and aphasia. Cortex, 2, 50-70.

8. Fry, D. B. (1959): Phonemic substitutions in an aphasic patient. Lang. Speech, 2, 52-61.

9. Goldman, R.\& Fristoe, M. (1969): Goldman-Fristoe test of articulation. American Guidance Service, Inc., Minnesota. 
10. Goodglass, H. \& Kaplan, E.'(1972): The assessment of aphasia and related disorders. Lea \& Febeger, Philadelphia.

11. Hyman, L. M.(1975): Phonology: Theory and analysis. Holt, Rinehart \& Winston, U.S. A.

12. Jakobson, R. (1968): Child language, aphasia and phonological universals. Mouton, The Hague.

13. Jakobson, R., Fant, G. \& Halle, M. (1961): Preliminaries to speech analysis. M.I.T. Press. Cambridge, Massachusetts.

14. Johns, D. F. (1970): Application of experimental evidence in the treatment of apraxia of speech. Paper presented to the American Speech Hearing Association Convention.

15. Johns, D. F. \& Darley, F. L. (1970): Phonemic variability in apraxia of speech. J. Speech Hear. Res., 13(3), 556-583.

16. Johnson, W., Darley, F. L. \& Spriestersbach, D. C. (1963): Diagnostic methods in speech pathology. Harper \& Row, New York.

17. Ladefoged, P., De Clerk, J., Lindau, M.\& Papcun, G. (1972): An auditory-motor theory of speech production. Unpublished paper, U.C.L.A. Working Papers in Phonetics, 22, 48-75.

18. Lecours, A. R, \& Lhermitte, F. (1973): Phonemic paraphasias: Linguistic structures and tentative hypotheses. In Psycholinguistics and. Aphasia, Goodglass, H. \& Blumstein, S. (Eds.). The Johns Hopkins University Press, Baltimore.

19. Lieberman, P. (1972): Speech acoustics and perception. The BobbsMerrill Company, Inc., U. S. A.

20. Martin, A. D. (1974): Some objections to the term apraxia of speech. J. Speech Hear. Dis., 39(1), 54-63.

21. Martin, A. D. \& Rigrodsky, S. (1974a): An investigation of phonological impairment in aphasia. Part I. Cortex, 10(4), 317-328.

22. Martin, A. D. \& Rigrodsky, S. (1974 b): An investigation of phonological impairment in aphasia. Part II. Cortex, 10(4), 329-346.

23. Martin, A. D., Wasserman, N. H., Gilden, L., Gerstman, L. \& West, J. (1975): A process model of repetition in aphasia: An investigation of phonological and morphological interactions in aphasic error performance. Brain Language, 2(4), 434-450.

24. McReynolds, L. V. \& Engmann, D. L. (1975): Distinctive feature analysis of misarticulations. University Park Press, Baltimore.

25. McReynolds, L. V. \& Huston, K. (1971): A distinctive feature analysis of children's misarticulations. J. Speech Hear. Dis., 36(2), 155 . 166.

26. Menyuk, P. (1968): The role of distinctive features in children's acquisition of phonology. J. Speech Hear. Res., 11(1), 138-146.

27. Rosenbek, J. C., Lemme, M. L., Ahem, M. B., Harris, E. H. \& Wertz, R. T. (1973): A treatment for apraxia of speech in adults. J. Speech Hear. Dis., 38(4), 462.472.

28. Saling, M. (1976): Lecturer, Department of Psychology, University of the Witwatersrand, Johannesburg, Personal Communication.

29. Schuell, H. (1966): Some dimensions of aphasic impairment in adults considered in relationship to investigation of language disturbance in children. Brit. J. Dis. Commun., 1(1), 33.45. 
30. Schuell, H., Jenkins, J. J.\& Jiminez-Pabon, (1964): Aphasia in adults. Harper \& Row, New York.

31. Sankweiler, D. \& Harris, K.S. (1973): Some phonological implications of aphasic speech. In Psycholinguistics and Aphasia, Goodglass, H. \& Blumstein, S. (Eds.). The Johns Hopkins University Press, Baltimore.

32. Siegenthaler, B. M.\& Haspiel, G. S. (1968): Discrimination by identi: fication of pictures. Pennsylvania State University Speech and Hearing Clinic.

33. Spreen, O. (1968): Psycholinguistic aspects of aphasia.J. Speech Hear. Res., $11(3), 467.480$.

34. Standel, J. J., Gardner, J. O. \& Hannah, E. P. (1974): Distinctive feature analysis. In Applied linguistic analysis, Hannah E. P. (Ed.). Joyce Publications, California.

35. Walsh, H. (1974): On certain practical inadequacies of distinctive feature systems. $J$. Speech Hear. Dis., 39(1), 32-43.

36. Winitz, H. (1975): From syllable to conversation. University Park Press, Baltimore.

\section{Books on Speech and Hearing}

\section{CONSULT}

CAMPUS BOOKSHOP

34. Bertha Street,

P.O. Box 31361

BRAAMFONTEIN 2017

Telephone 39-1711

WESTDENE FEDIO BOOKS

35/6 Nedbank Plaza, 175 Beatrix Street PRETORIA

Telephone 2-6336

LOGANS UNIVERSITY BOOKSHOP ... 227/9 Francois Road, DURBAN

Telephone 35-4111

Overseas publications obtained promptly.

Nationwide mail-order senvice. 


\section{MODERN HEARING AIDS (PTY) LTD}

\section{FOR}

Hearing Alds - A comprehensive range comprising the latest Microson directional models - Unitron high level compression models.

Ear Moulds - We specialise in ear mould technology to the great benefit of our patients - we also supply instant mould kits to schools.

Audiometers - Audiotone portable screening and diagnostic units at the best prices available.

Sound Proof Booths and Earmutfs High Quality locally manufactured products

TV accessories - manufactured by ourselves

\section{WE RE 305 Rand Central 165 Jeppe St Johannesburg}

Tel: 37-1774 